\title{
Improved Tunnel Resistance of Silvered-Polymer Mirrors
}

Gary Jorgensen

Paul Schissel

Cheryl Kennedy Yvonne Shinton

Douglas Powell

James Siebarth

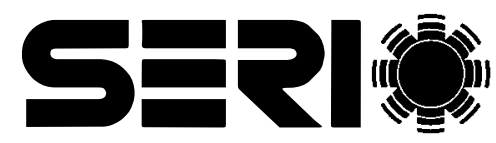

Solar Energy Research Institute A division of Midwest Research Institute operated for the U.S. Department of Energy under contract No. DE-AC02-83CH10093 
On September 16, 1991, the Solar Energy Research Institute was designated a national laboratory, and Its name was changi to the National Renewable Energy Laboratory.

\title{
NOTICE
}

This report was prepared as an account of work sponsored by an agency of the United States government. Neither the United States government nor ai agency thereof, nor any of their employees. makes any warranty, express or implied. or assumes any legal liability or responsibility for the accuracy. cor pleteness. or usefulness of any information. apparatus. product, or process disclosed. or represents that its use would not infringe privately owned righi Reference herein to any specific commercial product, process, or service by trade name, trademark, manufacturer, or otherwise does not necessarily co stitute or imply its endorsement. recommendation, or favoring by the United States government or any agency thereof. The views and opınions of autho expressed herein do not necessarily state or reflect those of the United States government or any agency thereof.

\author{
Printed in the United States of Amerıca \\ Available from: \\ National Technical Information Service \\ U.S. Department of Commerce \\ 5285 Port Royal Road \\ Springfield. VA 22161
}

Price: Microfiche A01

Printed Copy $\mathrm{AO} 3$

Codes are used for pricing all publications. The code is determined by the number of pages in the publication. Information pertaining to the pricıng cod can be found in the current issue of the following publications which are generally avallable in most libraries: Energy Research Abstracts (ERA): Gove, ment Reports Announcements and Index (GRA and I); Scientific and Technical Abstract Reports (STAR); and publication NTIS-PR-360 avallable from NT at the above address. 


\section{Table of Contents}

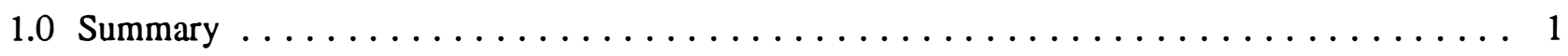

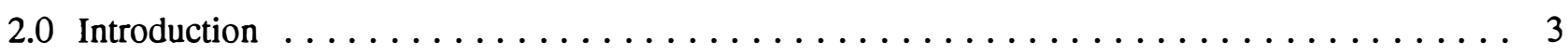

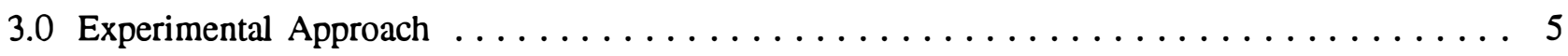

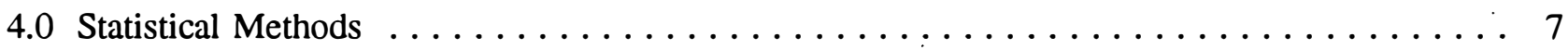

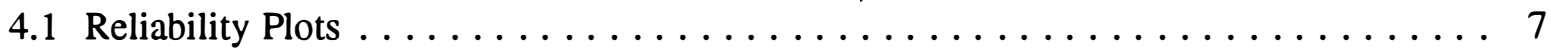

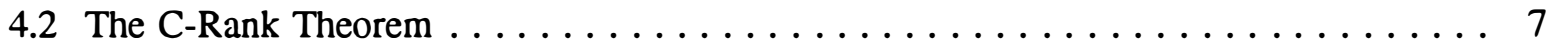

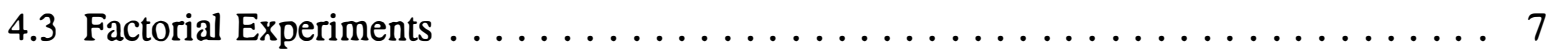

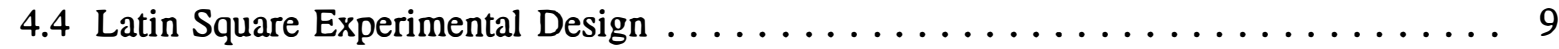

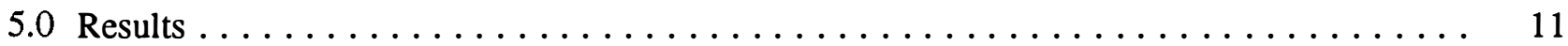

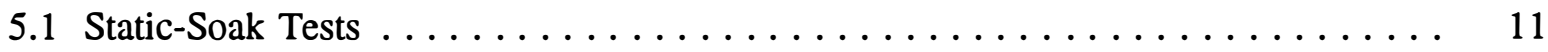

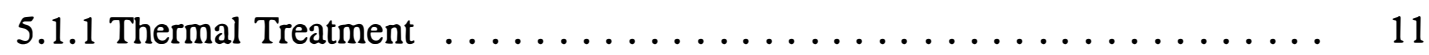

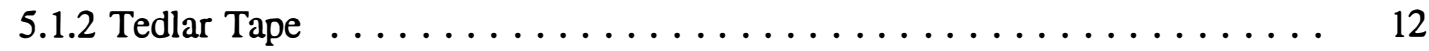

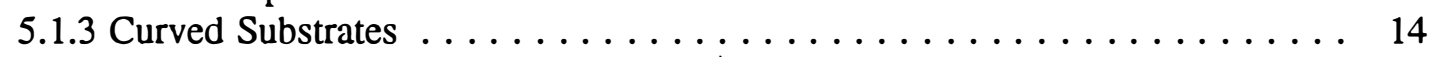

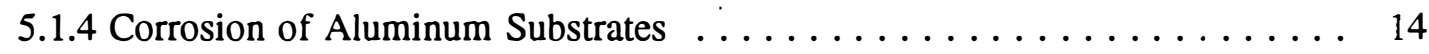

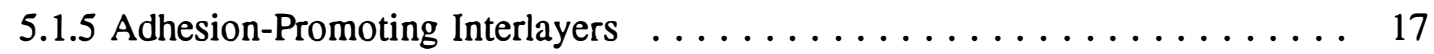

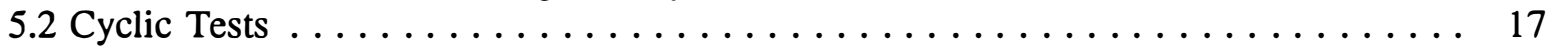

5.2.1 Thermal Treatment and Tedlar Tape ...................... 17

5.2.2 Edge Joining and Alternative Deposition Processes . . . . . . . . . . 21

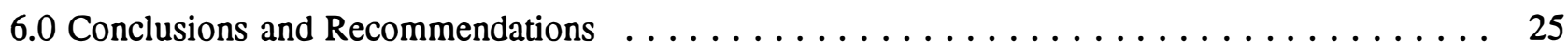

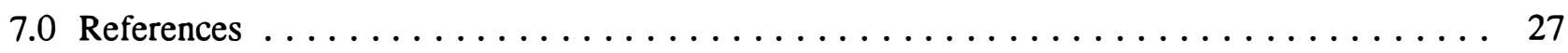




\section{List of Figures}

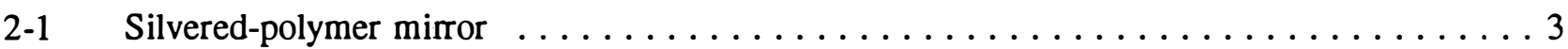

4-1 Reliability plot of percent survivors vs. days in water for

"standard" 18-x-24-inch ECP-305 in static-soak screening test $\ldots \ldots \ldots \ldots \ldots \ldots \ldots$

4-2 Latin Square design for sample parameter cyclic tunnel experiment . . . . . . . . . . 9

5-1 Days to failure as function of time/temperature thermal treatment of

18-x-24-inch ECP-305 in static-soak screening test $\ldots \ldots \ldots \ldots \ldots \ldots \ldots \ldots \ldots \ldots$

5-2 Effect of edge treatment on percent survivors vs. days in water for

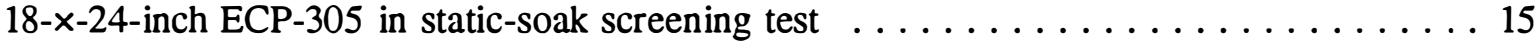

5-3 Effect of curvature on percent survivors vs. days in water for

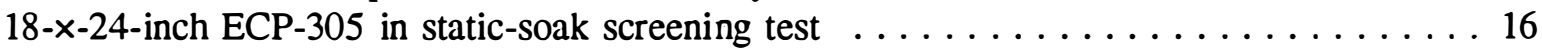

5-4 Effect of substrate on percent survivors vs. days in water for

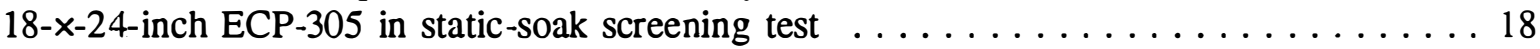

$5-5 \quad$ Basic construction of cyclic tunnel test samples $\ldots \ldots \ldots \ldots \ldots \ldots \ldots \ldots$

5-6 Effect of thermal treatment and edge tape on percent-intact samples of 9-x-24-inch

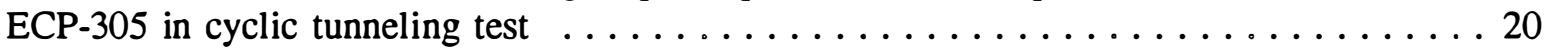

5-7 Percent-intact samples vs. number of cycles for 9-x-24-inch

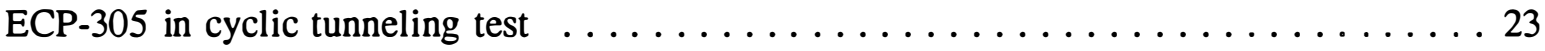




\subsection{Summary}

This report documents the research performed at the Solar.Energy Research Institute (SERI) during fiscal year (FY) 1991 to develop ways to prevent dela mination failure (known as tunneling) of silvered-polymer reflector materials. Several promising approaches have been identified and demonstrated that substantially reduce such failures. These approaches include (1) use of Tedlar edge tape rather than the manufacturerrecommended ECP-244 tape, (2) thermal treatment of laminated reflector/substrate constructions, and (3) application of silver to the polymer film through an alternative deposition process. Approaches 1 and 2 offer readily available engineering solutions to the delamination problem. Approaches 2 and 3 provide tunnel resistance over the entire surface of the reflector material, including the edges.

Tedlar (a polyvinyl fluoride from DuPont) tape is an opaque white tape available in different widths from $3 \mathrm{M}$ Company. The base material has demonstrated outstanding outdoor durability. It is only slightly more expensive than the 3M-recommended ECP-244 edge tape (\$0.20 vs. $\$ 0.15$ per linear foot) and is much easier to apply. The thickness of Tedlar tape is considerably less than ECP-244, and it is more pliable than ECP-244 (an aluminized acrylic). Its adhesive does not "set up" as aggressively as that of ECP-244, which allows it to be readily peeled and repositioned during application. In fact, Tedlar tape can easily be removed even after weathering. Even so, the Tedlar tape acts as an excellent water barrier. During the few times tunnels have been experienced in laboratory tests of Tedlar-protected samples, small tunnels (typically 2-3 inches long and $1 / 2-1$ inch wide) may appear but do not propagate catastrophically, presumably because the Tedlar tape provides an effective barrier to the rapid influx of water.

Thermal treatment of ECP-305 laminated to substrate materials has demonstrated outstanding resistance to tunneling. Temperatures in the range of $70-80^{\circ} \mathrm{C}$ have proven effective for treatment times as low as 4 hours. Samples that have been subjected to static and cyclic water exposure for extended periods of time (30-40 days) have been purposely damaged and retested. Tunnel failure has not occurred, indicating a resistance to delamination over the complete reflector area. The effect of thermal treatment on the tunneling resistance of curved configurations is being tested.

Alternative silver deposition techniques such as sputtering (rather than thermal evaporation) offer increased resistance to tunneling. One concern associated with this approach is increased processing cost due to lower production line throughput of metallized film. The interposition of thin layers of adhesionpromoting inorganic materials between the silver layer and the polymer film also provides enhanced delamination protection. 


\subsection{Introduction}

Use of solar thermal energy to generate electric power requires large mirrors to provide high levels of concentrated sunlight. Metallized polymeric reflector materials are significantly lighter in weight and potentially less expensive than conventional glass/metal mirrors. Additionally, they offer greater flexibility in system design. In particular, silvered-polymer reflectors enable the use of a stretched-membrane concept for concentrating collectors.

The success of such systems hinges on the service durability of the reflector materials. Several failure modes have been experienced in the field, including:

- Loss of reflectance caused by corrosion of the metal layer

- Degradation of optical performance from soiling and abrasion

- Delamination of the metal layer from the front protective polymer film.

Progress toward improved resistance to corrosion has been documented elsewhere [1-3]. The current status of soiling and cleaning efforts has been summarized in [4-6]. This report deals exclusively with research carried out at SERI to investigate ways of decreasing delamination failures known as tunneling.

Silvered-polymer mirrors (Figure 2-1) can experience a sporadic failure mode called tunneling. During tunneling the polymer separates from the silver metal in a characteristic pattern. Tunneling usually occurs when the mirror is exposed to high humidity, and it almost always begins at the edges of the polymer. Important exceptions occur when the mirror is damaged away from the edges; but even then internally formed edges play a role. For ECP-305, a commercial mirror manufactured by the 3M Company, the tunnels are usually about 1 inch wide and are separated by about 3 inches. Typically, a pattern of tunnels meanders over the complete mirror surface. Tunnel failures are sporadic. If water is allowed to accumulate on a large mirror, tunneling may begin within a few days.

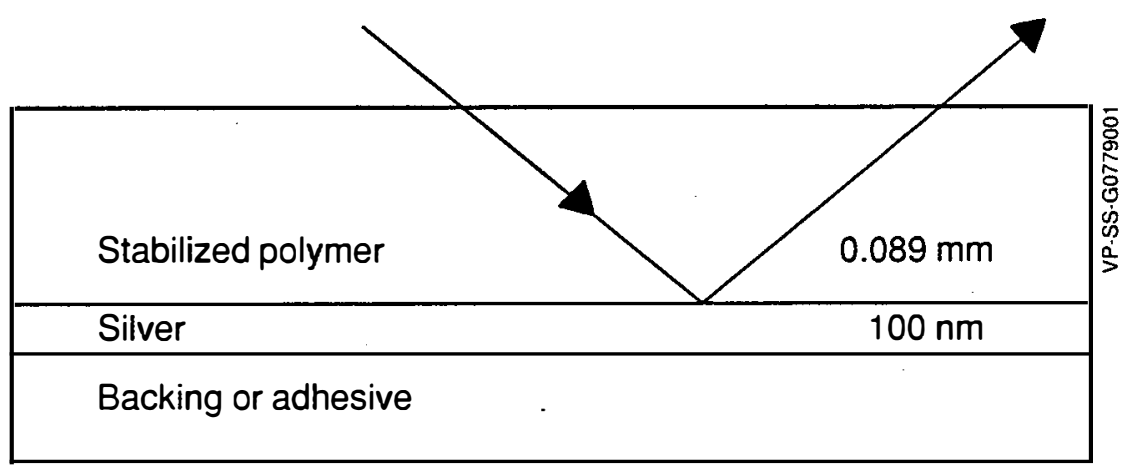

Figure 2-1. Silvered-polymer mirror 
SERI has undertaken an applied engineering/phenomenological approach to this problem. An important concern addressed in the literature [7] is the inherent weakness of the silver/polymethylmethacrylate (PMMA) bond. A series of screening tests has suggested several possible mechanisms that may take advantage of this intrinsically poor initial adhesion and drive the material to delamination failure. Much of the evidence points toward two important factors: (1) mechanical stress between the silver and polymer layers and (2) the presence of moisture.

The polymer film is known to absorb water. Absorption of bulk water can result in a chemical or physical reduction in the adhesive force between the silver layer and the polymer film. This process is apparently somewhat reversible [8] (i.e., absorption of water further weakens adhesion; as the laminate dries out, adhesion can improve). Such a cyclic process may ultimately weaken the adhesive bond beyond repair and result in catastrophic failure.

Another potential mechanism is direct stress build-up (i.e., noncyclic) above tolerable levels. This may occur by differential hygroscopic expansion of the front polymer relative to the substrate material (which holds the silver layer rigid by virtue of an aggressive adhesive). Thermally induced stresses, caused by dissimilar thermal expansion coefficients of the polymer and the substrate material, may also be important.

Tunneling begins almost exclusively at edges. One reason for this may be the attack and ingress of water along the silver/polymer interface from an edge. Another reason may be stress concentrations formed at flaws introduced in the edges of the brittle polymer when the mirrors are cut to size. 


\subsection{Experimental Approach}

Delamination failure in the field can be described as random and sporadic. Thus, to solve the tunneling problem, it was important to develop an accelerated exposure test that replicates field failures in a controlled manner in the laboratory.

Numerous research programs have attempted to develop such an accelerated test $[9,10]$. An attempt was made to relate the adhesive force between the metal coating and the polymer film with the tendency to delaminate. Adhesion was measured using the American Society for Testing and Materials standard procedures such as the peel test and scratch test. Several drawbacks were found. The variance associated with comparative data sets was too large to allow statistically significant inferences to be made. Incremental improvements in adhesion could not be quantified because measurements often exhibited an "all-or-nothing" behavior. For example, in the scratch test samples either failed completely (e.g., silvered PMMA) or could not be made to fail at all (e.g., aluminized polyethylene terephthalate [PET]).

Another impediment was the difficulty of reproducing tunnel failures with laboratory-sized samples. A number of severe exposure conditions were attempted to induce delamination in 2-inch-by-3-inch samples. These included [9] long-term immersion in water, heating in moist air, and cyclic dipping in boiling water and liquid nitrogen. When failure did occur, it did not visually resemble the characteristic tunnel failure pattern observed in the field.

Based upon previous work at SERI and experience at the 3M Company [8], researchers found that immersion of larger-sized samples ( $\geq 5$ inches by 8 inches) in baths of tap water at room temperature could induce tunnel failure that resembled the failure experienced in the field. These exposure conditions have been used extensively at SERI as an accelerated screening test to identify and investigate various factors that may contribute to tunneling. Sample parameters that have been found to influence the tunneling process include:

- Sample size

- Substrate type (material)

- Edge cutting (preparation) technique

- Edge sealing (protection) method

- Reflector material construction (adhesion)

- Seam joining methods

- Metal deposition procedure

- Thermal treatment.

Several different variations of each factor are plausible, resulting in a large matrix of screening combinations.

A second, more elaborate accelerated test has been developed at SERI. Samples are alternately immersed in a water bath $\left(23^{\circ} \mathrm{C}\right)$ and dried in an oven $\left(50^{\circ} \mathrm{C}\right)$. Such cycling is more representative of the real-world wet/dry environment. When relevant variables have been identified by SERI's accelerated screening test, accelerated cyclic testing is used with statistically designed experiments [11] to explore tunnel failure in greater detail.

These accelerated tunneling tests are in their infancy. Although they can induce tunnel failures that qualitatively replicate those observed in the field, they employ considerably harsher conditions than those found in the real world. Extrapolation of laboratory results to outdoor survival rates is neither possible nor intended at this time. The benefit of these tests is that they generate data that can be useful for purposes of comparison. 


\subsection{Statistical Methods}

\subsection{Reliability Plots}

A simple graphical presentation of reliability is obtained by plotting the percent survival of a sample set as a function of time in a particular test. A basic plot is shown is Figure 4-1. Ten samples were placed in the static water test. These particular samples consisted of ECP-305 (18 inches by 24 inches) mounted on aluminum. The samples were cut from a roll whose edges were slit by the $3 \mathrm{M}$ Company. The samples were cut from the roll with a heated knife, and the $3 \mathrm{M}$-produced edges were left intact. These samples were edge-taped with ECP-244 tape and are representative of the current best practice. Figure 4-1 graphically represents the current standard against which improvements are to be compared.

\subsection{The C-Rank Theorem}

The results of Figure 4-1 can be made quantitative by using the C-Rank Theorem. This theorem is a nonparametric statistical test that is used to evaluate sample reliability, $R_{C}$, at a test confidence level $C$ [12]. The test is used when $\mathrm{k}$ failures occur out of $\mathrm{n}$ items tested at a particular test time. The basic relation is:

$$
R_{C}=1-[C \text { rank of the }(k+1) \text { st-order statistic in }(n+1)]
$$

In general, when $\mathrm{k} \neq 0$, the ranks are presented numerically, and tabular data is used [13]. In the special case when no failures occur, $\mathrm{k}$ is zero and a simple formula applies. For $\mathrm{k}=0$ :

$$
\mathbf{R}_{\mathrm{C}}=(1-\mathrm{C})^{1 /(\mathrm{n}+1)}
$$

For example, the data in Figure 4-1 show that at 40 days in the water bath 7 samples failed $(k=7)$ out of a set of $10(n=10)$. A test confidence level of $C=0.95$, that is $95 \%$, is desired. Therefore, using equation (1) and the $95 \%$ ranks for the $k+1=8$ order statistic in $n+1=11$ (see reference 13), we obtain:

$$
\mathbf{R}_{\mathrm{C}}=1-[0.8637]=0.136
$$

Thus, for 95 out of 100 experiments, only $13.6 \%$ of the samples prepared and subjected to the test conditions consistent with Figure 4-1 will survive for 40 days.

\subsection{Factorial Experiments}

The multitude of sample parameters that are believed to influence tunneling (discussed in the Section 3 of this report) give rise to a large number of possible combinations of prepared samples to be tested. To improve confidence in predicted results, replicated samples are required, which further expands the size of the sample set. In order to reduce the number of samples, a factorial design [11] is used in some tests. This represents an economical approach to experimentation because it avoids having to test every possible combination of factors.

For experiments in which combined effects of two or more variables are believed to be important, the interactions of such treatments can be evaluated by using a factorial design. Another benefit of these experimental designs is that standard statistical analyses can readily be applied to measured data $[14,15]$. Analysis-of-variance (ANOVA) methods can be used to identify which factors are statistically significant (and which variables are of lesser importance) at a given level of confidence. Interaction effects between factors can be evaluated, and both linear and curvilinear elements can be estimated. 


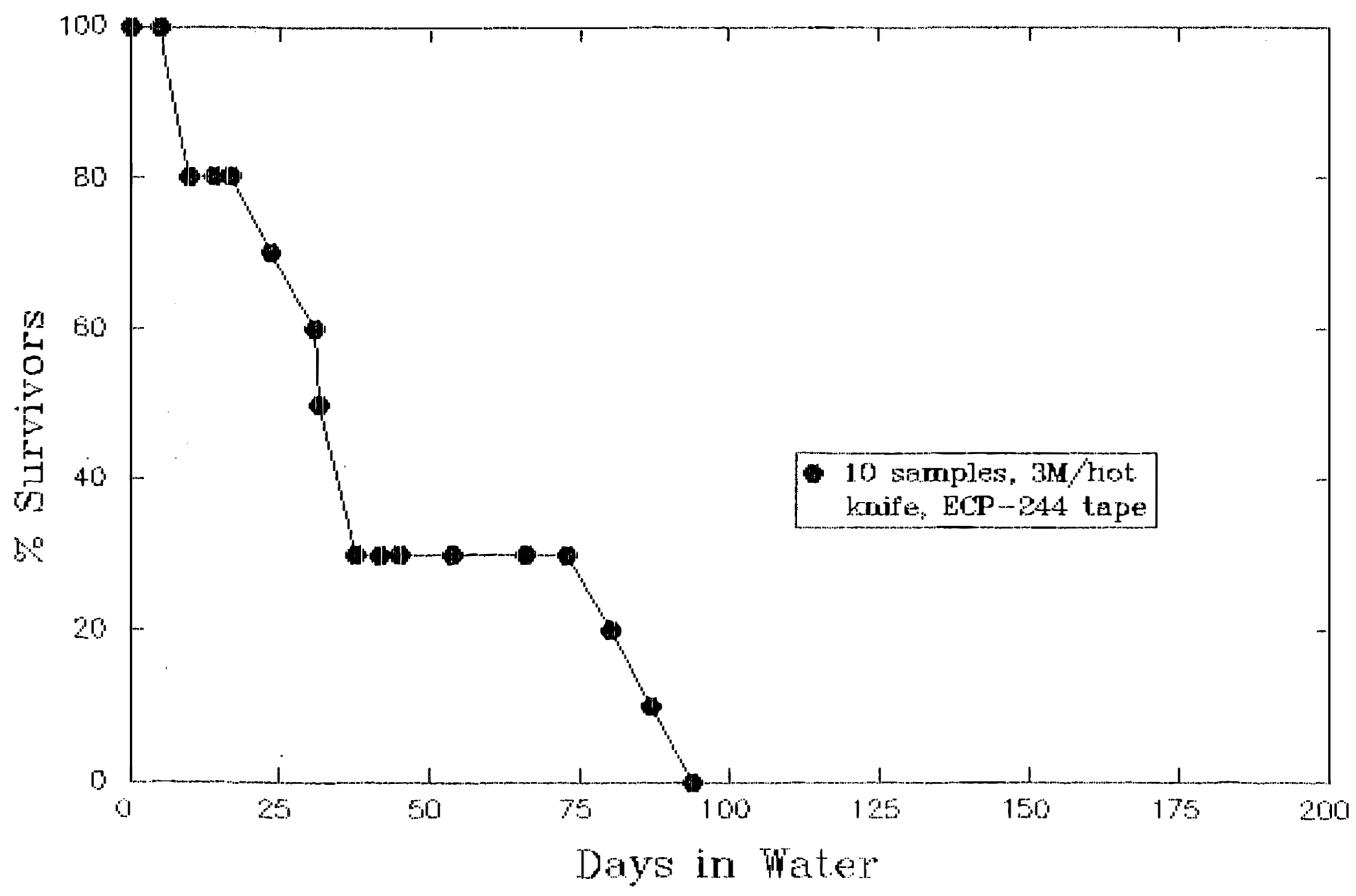

Figure 4-1. Reliability plot of percent survivors vs. days in water for "standard" 18-x-24-inch ECP-305 in static-soak screening test 


\subsection{Latin Square Experimental Design}

Latin Square experimental design [11] is a special case of factorial design in which no interactions are present and each factor has the same number of treatments, which is equal to the total number of factors. As an example, one cyclic experiment was designed to test three factors each at three levels. The three factors (and their respective levels) were edge cutting technique (paper cutter, hot knife, laser), edge tape (ECP-244, Tedlar, silicone), and substrate (aluminum, 304 stainless steel, painted aluminum). This results in 27 different possible sample configurations (i.e., $3^{3}$ ). By using an appropriate experimental design (shown schematically in Figure 4-2), only selected combinations of parameters need to be tested. The number of samples can thereby be reduced from 27 to only 9, and meaningful information will still be obtained about all factors.

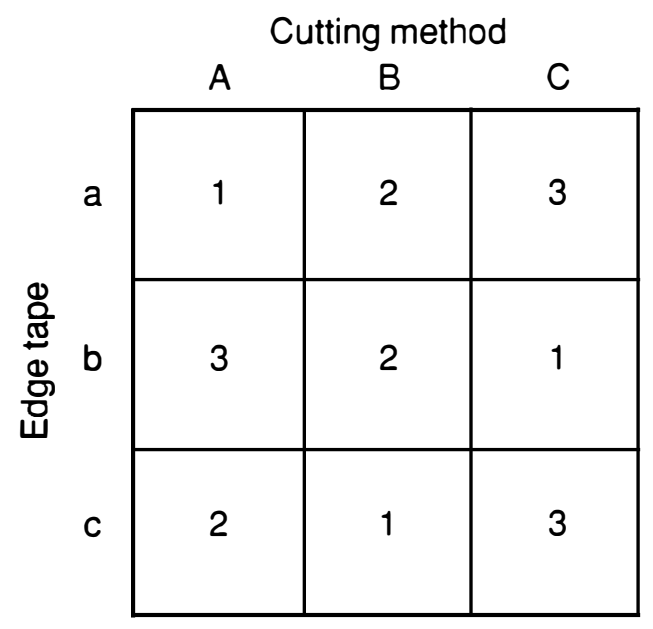

Cutting method

$A=$ Paper cutter

$B=$ Hot knife

$\mathrm{C}=$ Laser

Edge tape

$a=$ ECP-244

b $=$ Tedlar

$c=$ Silicone

Substrate

1 = Aluminum

$2=304$ stainless steel

3 = Painted aluminum

Figure 4-2. Latin Square design for sample parameter cyclic tunnel experiment 


\subsection{Results}

Two types of experiments have been used to identify relevant parameters and to quantify tunnel resistance of candidate silver polymer reflector materials. These two approaches (a static water-soak test and cyclic testing) indicate several promising ways to avoid delamination failure. One technique is to thermally treat the silver polymer reflectors (after lamination to substrate material) prior to service. Another is to use an alternative edge tape (Tedlar) rather than the standard ECP-244. Finally, deposition of silver onto the polymer film by a sputtering process results in a dramatic improvement in tunnel resistance compared to evaporative deposition used with ECP-305.

Both the thermal treatment and the alternative deposition approach have the additional benefit of providing tunnel resistance over the entire reflector area as well as near edges. These approaches have an inherent measure of protection against hail or vandalism damage, and they eliminate the expense of purchasing and applying the edge tape.

\subsection{Static-Soak Tests}

Two procedures have resulted in major improvements in performance in the static-soak test. The first procedure uses a process of curing or annealing the samples (after they are laminated to substrates) by heating them in an air oven. The second procedure uses Tedlar tape to protect the mirror edges.

\subsubsection{Thermal Treatment}

Flat (18 inches by 24 inches) samples of ECP-305 that were rimmed with a razor, had no edge tape protection, and were cured at $80^{\circ} \mathrm{C}$ for 65 hours had no tunneling failures. Some samples have been in the water for up to 125 days and, for example, at $t=40$ days there were no tunneling failures for 31 samples. From equation 2; at a test confidence of $\mathrm{C}=0.95$, the sample reliability is:

$$
R_{C}=(1-0.95)^{1 / 32}=0.91
$$

That is, a sample reliability of $91 \%$ would be expected in at least $95 \%$ of the tests conducted. This compares to $R_{C}=0.136$ for the reliability of the currently used constructions. Five intentionally poor samples were also made where all edges were formed with a razor, no edge tape was used, and the samples were not cured. Within 28 days all five samples had tunneled. From equation 1:

$$
\begin{aligned}
\mathbf{R}_{95} & =1-[95 \text { rank of } k+1=6 \text { of } n+1=6] \\
& =1-[0.9915] \\
& =0.0085
\end{aligned}
$$

Thus curing has raised the reliability from less than $1 \%$ to $91 \%$ in the static-soak test.

To test the effectiveness of the thermal treatment at points of the mirror surface interior to the edges, 6 of the above 31 samples with $91 \%$ reliability were each drilled, scratched, and hit with a hammer and replaced in the water. These 6 samples had no tunnel failures after an additional 81 days of exposure to water.

One concern associated with thermally treating polymeric reflectors is the potential for adversely affecting optical performance. Small ( 2 inches by 2 inches) samples of ECP-305 were mounted on glass substrates, and specular reflectance measurements were made at 4,8 , and $12 \mathrm{mrad}$ full acceptance angle. The samples were then subjected to $80^{\circ} \mathrm{C}$ for 65 hours, and specular reflectance measurements were repeated. No discernable difference in specular reflectance was found even for the 4 mrad measurements. These samples are currently undergoing accelerated exposure in an Atlas Weather-Ometer. 
The temperature $\left(80^{\circ} \mathrm{C}\right)$ and time (65 hours) for the curing process were arbitrarily chosen. Preliminary results are available from an ongoing screening experiment designed to investigate the time/temperature tradeoffs associated with thermal treatment of silvered-polymer reflectors for delamination resistance. Two samples each (18 inches by 24 inches) of ECP-305 were laminated to aluminum substrates and thermally treated at $60^{\circ}, 70^{\circ}$, and $80^{\circ} \mathrm{C}$ for 4,22 , and 40 hours prior to testing. No edge protection (tapes, etc.) was used. Samples were subjected to static-soak exposure. Results are presented in Table 5-1.

\begin{tabular}{||c|c|c|c||}
\hline Table 5-1. & \multicolumn{1}{l|}{$\begin{array}{l}\text { Days to tunnel failure for 18-x-24-inch samples of ECP-305 } \\
\text { mounted on bare aluminum substrates, no edge protection, } \\
\text { as a function of thermal pretreatment at } 60^{\circ} \mathrm{C}, 70^{\circ} \mathrm{C} \text {, and } 80^{\circ} \mathrm{C} \\
\text { applied for 4, 22, and 40 hours. Two samples were prepared } \\
\text { at each condition (separated by }) .\end{array}$} \\
\hline \multirow{2}{*}{ Temperature $\left({ }^{\circ} \mathrm{C}\right)$} & 4 & 22 & 40 \\
\cline { 2 - 5 } & 4 & $47 / 47$ & $7 / 26$ \\
\hline 60 & $3 / 4$ & $58 />111$ & $>111 />111$ \\
\hline 70 & $58 / 75$ & $>111 />111$ & $>111 />111$ \\
\hline 80 & $>111 />111$ & & \multicolumn{3}{|c||}{ Time (hours) } \\
\hline
\end{tabular}

To further examine these results, response curves were generated (Figure 5-1) for the time to failure $(\mathrm{F}$, days) as a function of temperature $\left(\mathrm{T},{ }^{\circ} \mathrm{C}\right.$ ) and duration (t, hours) of thermal treatment. An experimental design tool [15] was used to analyze the data presented in Table 1. One drawback to this process is that many of the samples (including all of those treated at $80^{\circ} \mathrm{C}$ ) have not yet failed. A time to failure of 125 days (consistent with the longest lifetime of thermally treated samples in the static soak tests discussed previously) was assigned for all nonfailed samples. Although this artificially biases how well a model can be made to fit the data (because the factor of time is held constant at the upper temperature), a qualitative indication of the time to failure response to time/temperature thermal treatment can be obtained. A linear model was used:

$$
F=A_{0}+A_{1} t+A_{2} T
$$

Using quadratic terms in the model did not improve the fit of the data (due to the lack of a complete data set discussed previously). Figure 5-1 suggests that thermal treatment at a temperature of $80^{\circ} \mathrm{C}$ for a time duration as short as 4 hours can provide significant resistance to tunneling.

Researchers at SERI are in the process of quantifying the effect of thermal treatment on improved adhesion between the silver layer and the polymer film. An adhesion test unit has been procured, and preparation of ECP-305 test samples that are thermally treated over a range of times and temperatures is currently under way.

\subsubsection{Tedlar Tape}

The calculation of equation 4 is based on the observation that no tunnel failures occurred. For uncured samples without edge tape, tunnels occur rapidly and meander over the entire mirror surface. Curing can inhibit tunneling, but after one to several months in the water there is a border of incursion of moisture that can vary from $1 / 16$ of an inch to almost an inch, and that degrades reflectance. Unlike tunneling, the edge incursion has relatively little effect upon the total reflectance of even small sample mirrors. The edge incursion is avoided by the use of Tedlar tape. 


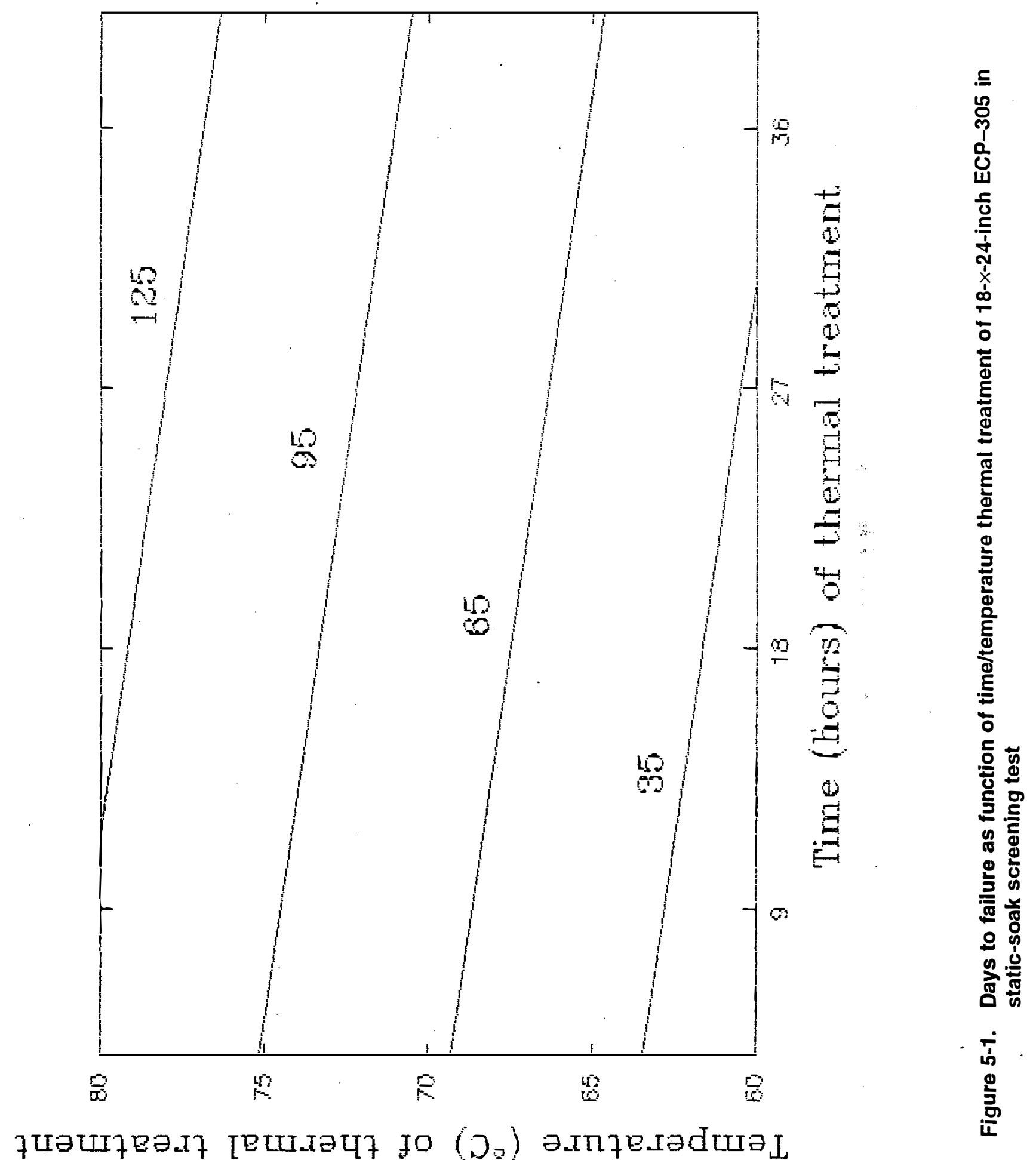


The second procedure to avoid tunneling uses Tedlar tape to protect the mirror edges. Data for samples with Tedlar edge tape are presented in Figure 5-2. At $\mathrm{t}=40$ days there are no failures for 15 samples. From equation 2 , at a test confidence of $95 \%$, the sample reliability is:

$$
R_{C}=(1-0.95)^{1 / 16}=0.83
$$

Of the 15 samples, 5 had all edges trimmed with a razor to intentionally create poor edges. The Tedlar prevented any failures for 44 days and only one failure occurred up to 180 days. Ten of these samples had all four edges trimmed with a heated knife to provide better edges. The first of the ten failed after 149 days. For comparison, the data in Figure 4-1 are also replotted in Figure 5-2. The improved performance of the Tedlar tape is evident. The positive effect of Tedlar tape is more striking if one compares the five samples that were also trimmed with a razor but had no edge tape (Figure 5-2). All five of these samples failed within 28 days, and the first sample failed in 1 day.

Presumably combining curing and the use of Tedlar tape would provide excellent protection; however, this combination has not been investigated.

\subsubsection{Curved Substrates}

Until recently, all delamination samples tested at SERI have been flat panels. Curved substrates were expected to introduce additional mechanical stresses on silvered polymer reflectors. These stresses could increase the likelihood of tunnel initiation and accelerate propagation. To explore this concern, tunnel experiments were carried out on curved samples in the static-soak screening baths. Recent success with heat treating samples of ECP-305 mounted on aluminum substrates prior to water immersion was incorporated into these tests.

Twelve samples of ECP-305 measuring 18 inches by 24 inches were laminated onto flat aluminum substrates and thermally treated at $80^{\circ} \mathrm{C}$ for 65 hours. These were than smoothly curved in one direction (along the 24-inch length) at a radius typical of the smallest radius of curvature (14.4 inches) expected in the field. After 19 days of water immersion, 7 out of 12 samples had tunneled (Figure 5-3). Most tunnels were narrow $(\approx 1$ inch wide) channels (rather than tunnel patterns covering the entire surface area) that ran the length of the material normal to the direction of curvature.

To investigate whether thermal treatment after bending provides any degree of tunnel resistance for curved samples, two additional sample sets were prepared. One set (10 replications) was laminated flat, curved, and then heat treated in the manner discussed in the previous paragraph. The other set ( 9 replications) was laminated onto curved substrates and then heat treated. All samples were trimmed with a razor blade; no edge protection (tape, etc.) was used.

After 5 weeks of testing, none of the samples whose final step was thermal treatment had tunneled (Figure 5-3). These encouraging results suggest that significant resistance to tunnel failure can be obtained by application of thermal treatment to ECP-305 laminated to curved surfaces. The thermal treatment should be carried out on reflector elements configured as near to their final form as possible.

\subsubsection{Corrosion of Aluminum Substrates}

A fairly high correlation of tunnel initiation at corrosion sites (aluminum hydroxide formation on the surface of the bare aluminum substrate) has been observed for curved samples. This effect has also been noted in cyclic and static experiments with flat samples. Such sites occurring at the edge of untaped ECP305 samples physically lift the edge of the reflector material and serve as tunnel initiation sites. For nonthermally treated samples, such initiation sites rapidly propagate over the entire surface of the sample. 


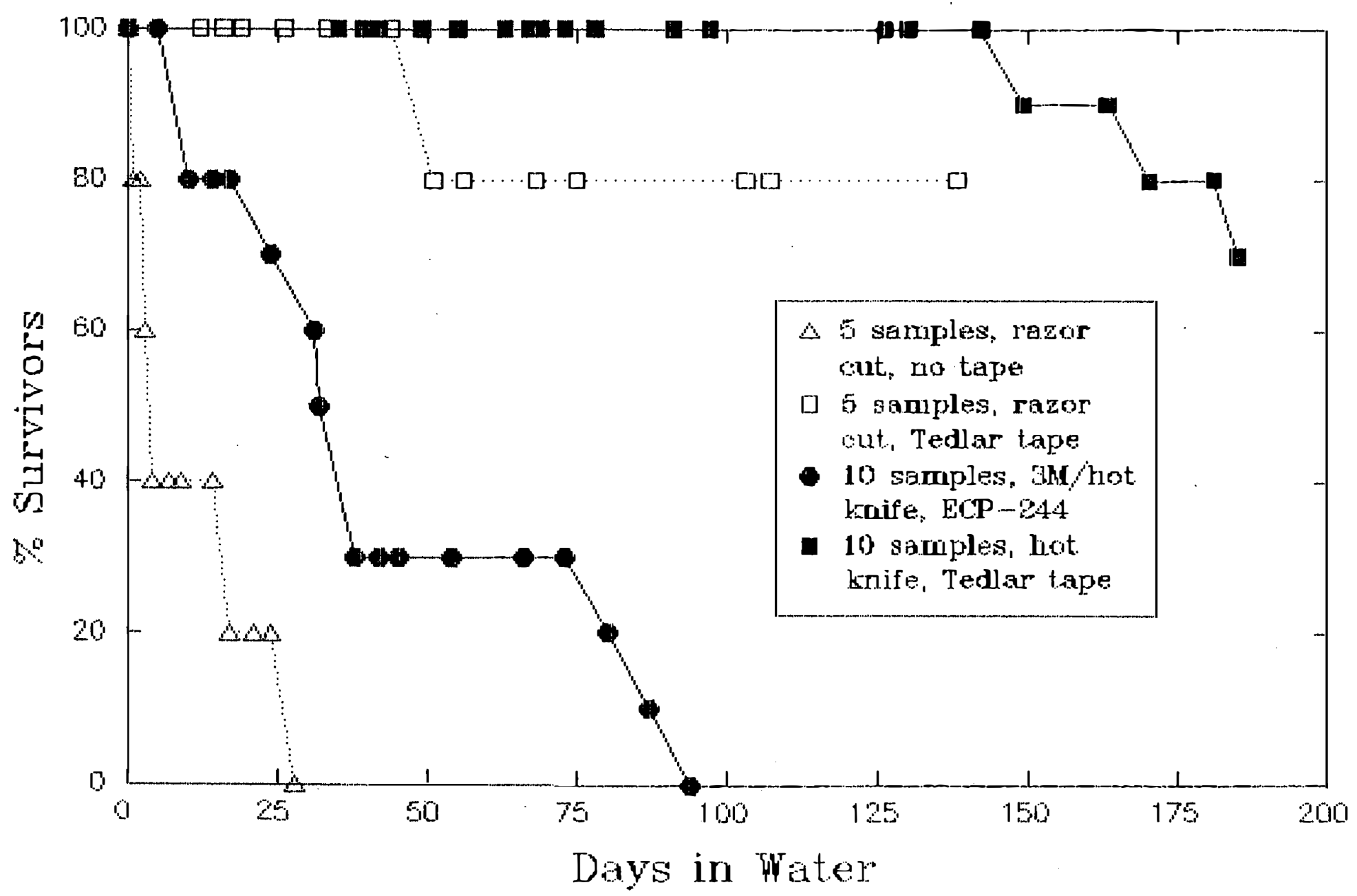

Figure 5-2. Effect of edge treatment on percent survivors vs. days in water for 18-x-24-inch ECP-305 in static-soak screening test 


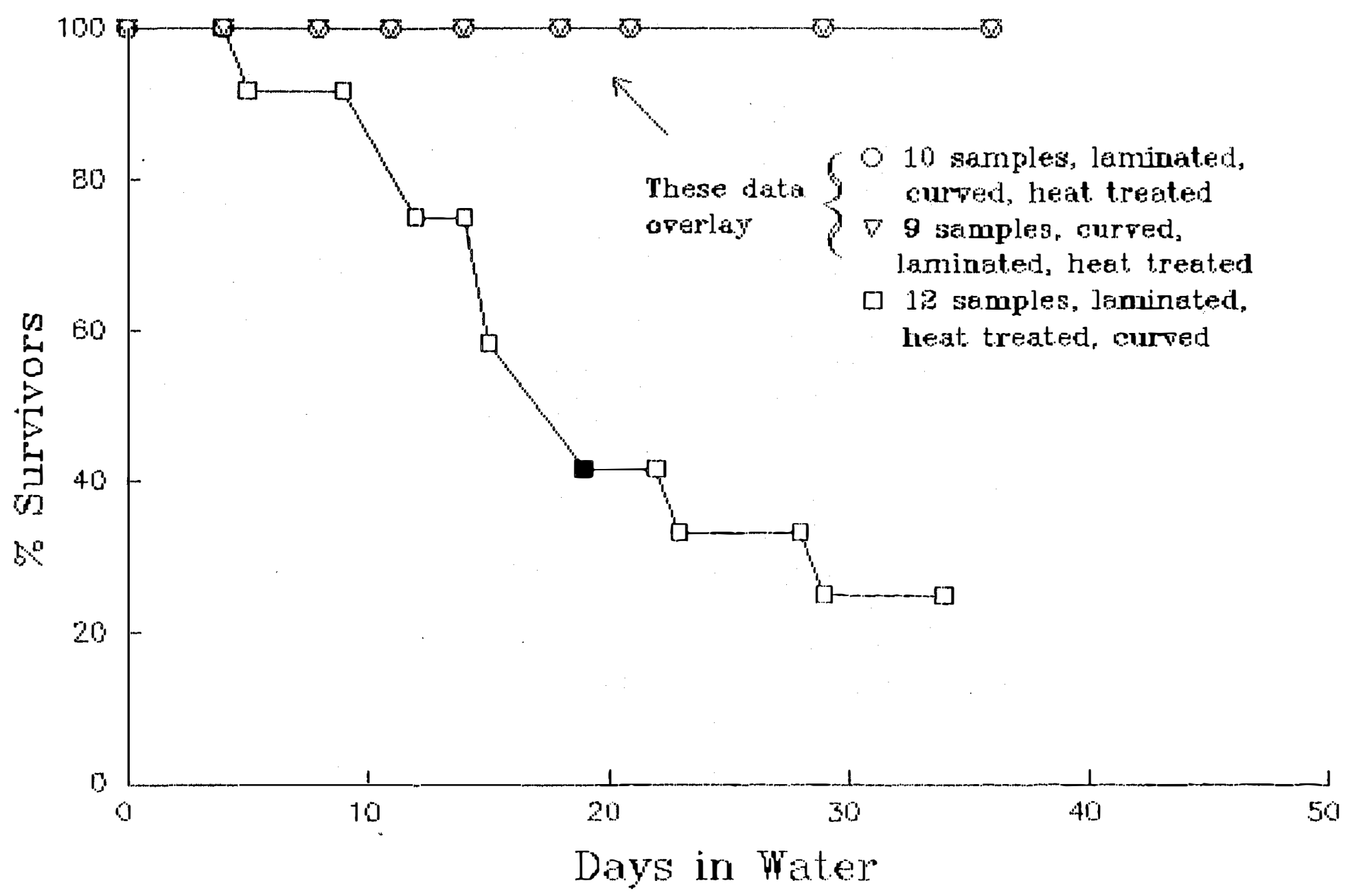

Figure 5-3. Effect of curvature on percent survivors vs. days in water for 18-x-24-inch ECP-305 in static-soak screening test 
Corrosion formation also gives rise to tunnel initiation at edges of thermally treated ECP-305. However, in the case of $80^{\circ} \mathrm{C}$ thermal treatment, such initiation sites do not propagate. This seems to be the principal beneficial aspect of this thermal treatment: tunnels, once initiated, do not continue to propagate. Unprotected edges of $80^{\circ} \mathrm{C}$ thermally treated samples of ECP-305 exhibit delamination growth at a rate of roughly $1 / 4$ of an inch per month of immersion in water. This is interpreted as a continual, slow progression of tunnel initiation without catastrophic propagation.

To further explore the effect on delamination of aluminum hydroxide corrosion site formation on bare aluminum, six samples (18 inches by 24 inches) of ECP-305 were cut with a hot knife and laminated to stainless steel substrates. No edge protection (tape, etc.) was used and no thermal treatment was provided. After 113 days of immersion in the static soak test, only one sample tunneled (at 35 days). For an identical sample set mounted on flat bare aluminum, five out of five samples tunneled by 34 days. These results are graphically displayed in Figure 5-4.

\subsubsection{Adhesion-Promoting Interlayers}

A third procedure that can delay tunneling is the use of thin, transparent, sputtered inorganic layers between the polymer and silver layers [10]. Such layers are effective in retarding tunneling in the staticsoak tests. However, after long-term weathering by an accelerated weathering device (Weather-Ometer) the inorganic layers have crazed and impaired specular reflectance. The effects of layer thickness and chemical composition are being studied to see if crazing can be avoided.

\subsection{Cyclic Tests}

Several cyclic tunnel experiments have been carried out. The basic sample construction is shown in Figure 5-5. All outer edges are protected by an angle bracket/C-channel clamping arrangement around the perimeter. Samples are cycled between a water bath $\left(27^{\circ} \mathrm{C}\right)$ and a drying chamber $\left(2\right.$ hours at $\left.50^{\circ} \mathrm{C}\right)$ and back to the water bath three times per week.

\subsubsection{Thermal Treatment and Tedlar Tape}

The first series of cyclic exposure tunneling experiments confirm the first two approaches discussed in Section 5.1: these approaches offer increased resistance to delamination in silver polymer reflector materials. The first procedure used an elevated temperature prebake (prior to cycling) of samples laminated to their substrate material. The second method substituted an alternative edge tape (Tedlar) for the standard ECP-244.

Samples ( 9 inches by 24 inches) with and without the standard ECP-244 edge tape were prepared to allow comparison on the basis of whether or not a precycling heat treatment of $80^{\circ} \mathrm{C}$ for $2 \frac{1}{2}$ days was effective. Based upon encouraging static-soak test results, samples with an alternative edge seal tape (Tedlar) were also included (nonbaked only). Eight replicates of each sample set were prepared.

After 70 days of testing ( 28 cycles) none of the 16 prebaked samples ( 8 with and 8 without ECP-244 edge tape) failed (Figure 5-6). In addition, none of the Tedlar edge-taped (nonbaked) samples exhibited tunneling. In contrast, seven out of eight samples without edge tape which were not pre-baked had tunnelled after 19 days ( 7 cycles). In the same time, five out of eight of the non prebaked samples with ECP-244 edge tape had failed.

As with the static soak tests discussed previously, aluminum hydroxide corrosion formation has also been observed with the cyclic test samples. These corrosion sites also lifted the ECP-244 edge tape, allowing 


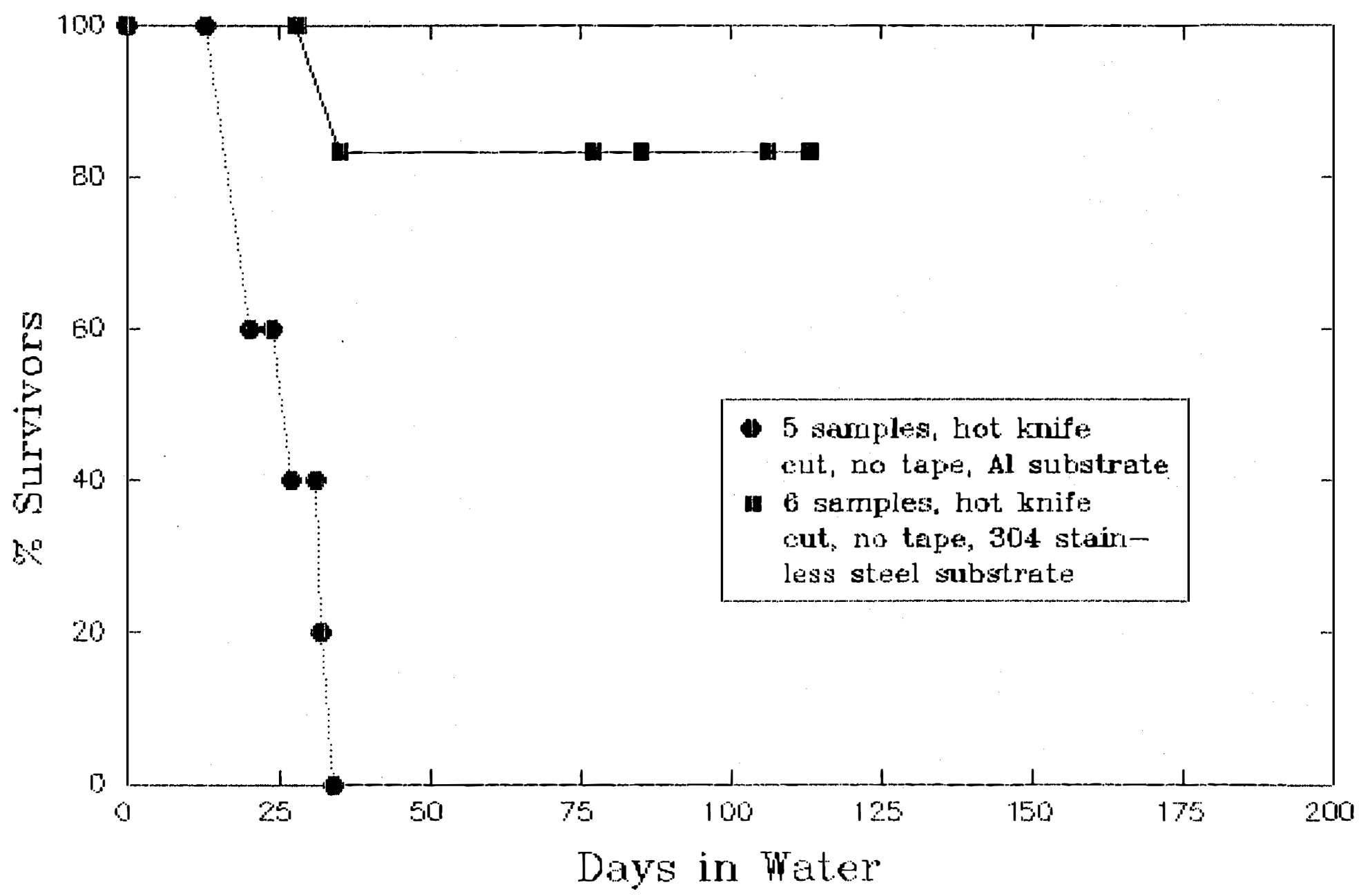

Figure 5-4. Effect of substrate on percent survivors vs. days in water for 18-x-24-inch ECP-305 in static-soak screening test 

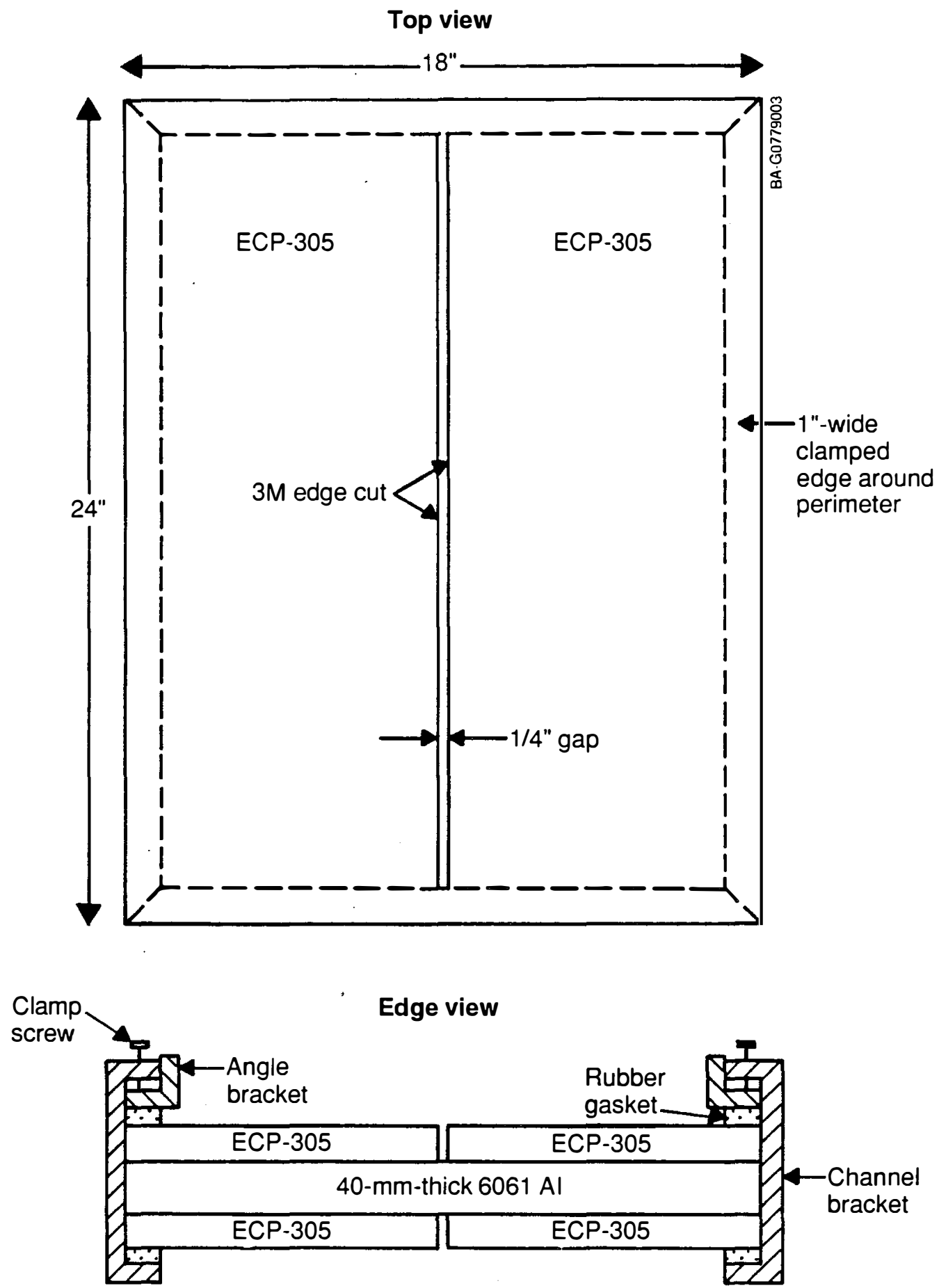

Figure 5-5. Basic construction of cyclic tunnel test samples 


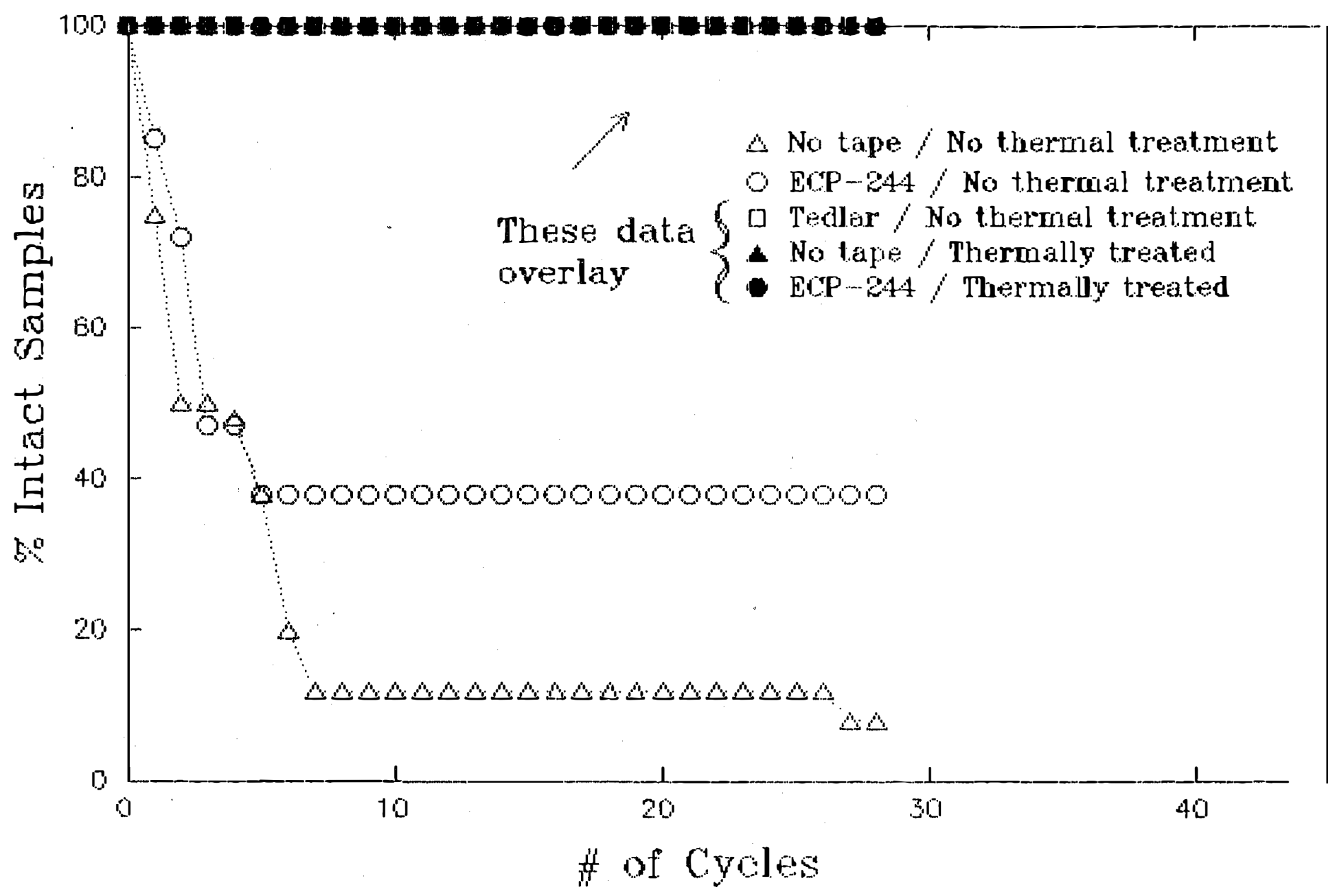

Figure 5-6. Effect of thermal treatment and edge tape on percent-intact samples of 9-x-24-inch ECP-305 in cyclic tunneling test 
water to reach the ECP-305, which can result in tunneling of nonbaked material. ECP-244 edge tape was also lifted in the case of thermally treated material, but tunnel failure was not observed (Figure 5-6). Moreover, the progression of edge tunnel initiation was not evident for thermally treated samples with ECP-244 edge tape. Aluminum hydroxide corrosion formation did not lift Tedlar tape.

To investigate whether thermal treatment provides tunnel resistance over the full mirror surface, several prebaked $\left(80^{\circ} \mathrm{C}\right.$ for $2 \frac{1}{2}$ days) samples that demonstrated resistance to edge tunneling were purposely damaged and returned to cyclic testing. Six prebaked samples that had not failed after 37 days (15 cycles) of testing were subjected to drill holes, knife cuts, and hammer blows. After an additional 92 days (43 cycles) of exposure, no tunnel propagation failures had occurred. (Following this period, a temperature excursion from $27^{\circ} \mathrm{C}$ to $43^{\circ} \mathrm{C}$ was experienced over a weekend in the cyclic water bath, and tunneling of all six samples ensued.)

\subsubsection{Edge Joining and Alternative Deposition Processes}

A second cyclic test was designed to investigate several ways to mitigate the tendency of silver polymer reflectors to exhibit delamination failure during service conditions.

Improved edge-joining processes were evaluated. A new solvent roller applicator was fabricated and was used to weld a bridge strip of unmetallized polymer film between adjoining edges of ECP-305 using acetone. A soldering iron with a 5/16-inch-wide tip was used to join inner edges with a heat weld. The soldering iron was also used to heat seal edges (i.e., without benefit of a bridge strip). Samples whose edges were cut and sealed by a laser were also included in this set of samples.

The replaceable reflector laminate recommended and installed (in Albuquerque) by Industrial Solar Technology Corporation (IST) was also tested. These were samples of ECP-305 laminated to a 10mm-thick polycarbonate film. The polycarbonate was mounted on aluminum substrates using a two-sided sheet adhesive (3M 9425). The adhesive on the aluminum side was a low-tack adhesive.

Several innovative SERI-sputtered constructions were included in the present set of samples as well. Sputtered silver samples were tested for comparison with evaporated silver (the standard ECP-305 configuration). Another set of samples incorporated edge masking during silver deposition to produce a $1 / 4$-inch-wide unsilvered edge to isolate the silver layer from possible edge flaws. Reflector stacks having an adhesion-promoting interlayer between the silver and the front surface polymer film were also tested.

Eight replicates of each sample set were prepared (except for the adhesion-promoting interlayer type for which only four samples were initially made). All outer edges were protected by an angle bracket/Cchannel clamping arrangement around the perimeter. With the exception of the bridge welded samples, no explicit edge protection (tape, etc.) was provided at the inner edges. To date, 40 cycles have been experienced in 97 days.

All samples were examined using a video microscope system prior to initiation of the test and every time the samples were cycled. Solvent-weld bridged samples appeared intact during initial visual inspection. Microscopic examination indicated that three of the four joined half samples were untainted; several small bond failures were found along both sides of the fourth pair of solvent-weld samples. Initially the heatwelded (as well as the heat-sealed) samples visually appeared poor. Roughly $25 \%$ (linear extent) of the heat-weld seams were found to be defective during microscopic inspection.

Inspection of bridge-welded samples was also carried out after roughly 2 hours of submersion in water. All solvent- and heat-welded samples had water entrapped underneath the bridge seam. To the extent that the edge-joining approach is intended to provide mechanical integrity between adjoining pieces of reflector 
material, the use of these bridged samples (even though they would not be water tight) was continued because (1) the bridge seams were mostly intact and would provide some degree of mechanical linkage, and (2) field application would be at least as difficult as in the laboratory, so, in terms of bond reliability, these samples represent the best conditions which can be expected to be encountered in the field.

Results of cyclic exposure are presented in Figure 5-7. The percentage of the untunneled area of each sample type is plotted as a function of the number of cycles experienced. The bridge-welded samples experienced rapid initial tunneling; by two cycles three of the solvent-weld samples and six of the heatweld samples had failed. In agreement with initial visual evaluation, the solvent-weld approach appears to provide better protection against delamination. This may be due to difficulties involved with getting enough heat through the bridge strip to provide a good bond with the ECP-305 film without melting the top strip. As with the previous cyclic test results (the prebaking thermal treatment), heat treating the edges appears to be beneficial. When sufficient heat is applied to the ECP-305 film edges (i.e., when the bridge strip does not effectively insulate the underlying silvered polymer), relatively improved tunnel resistance occurs (heat-sealed samples in Figure 5-7).

The laser cut/sealed samples experienced rapid catastrophic failure. All eight samples had completely tunneled by the third cycle. This was somewhat surprising because pretest microscopic examination revealed the laser sample edges to be the least blemished and most free from microcrack edge flaws.

In general, the sputtered-silver samples performed better than previously tested evaporated-silver (standard ECP-305) samples. Indications in the literature are that better adhesion is obtained by the more energetic sputtering process. One drawback with this approach may be increased cost due to much lower throughput of metallized film on the production line. None of the edge-masked sputtered-silver samples have delaminated. Only minor tunnel initiation has been experienced by the nonmasked sputtered-silver samples. One sample (out of four) with an adhesion-promoting layer between the silver and the polymer film has partially tunneled. These later samples were made during a period when problems were being experienced with SERI's magnetron sputtering unit. The unit has been repaired, and eight additional samples have been prepared to clarify these results. After 19 cycles (in 48 days), none of these recent samples have tunneled.

In contrast to outdoor exposure results from Albuquerque, none of the replaceable laminate samples have experienced tunneling. Compared to a previous replaceable reflector candidate (which used a polyester film as the intermediate backing layer and a lower tack 3M adhesive, namely, 9415) the present samples have not lifted up from the substrate during water submersion. 


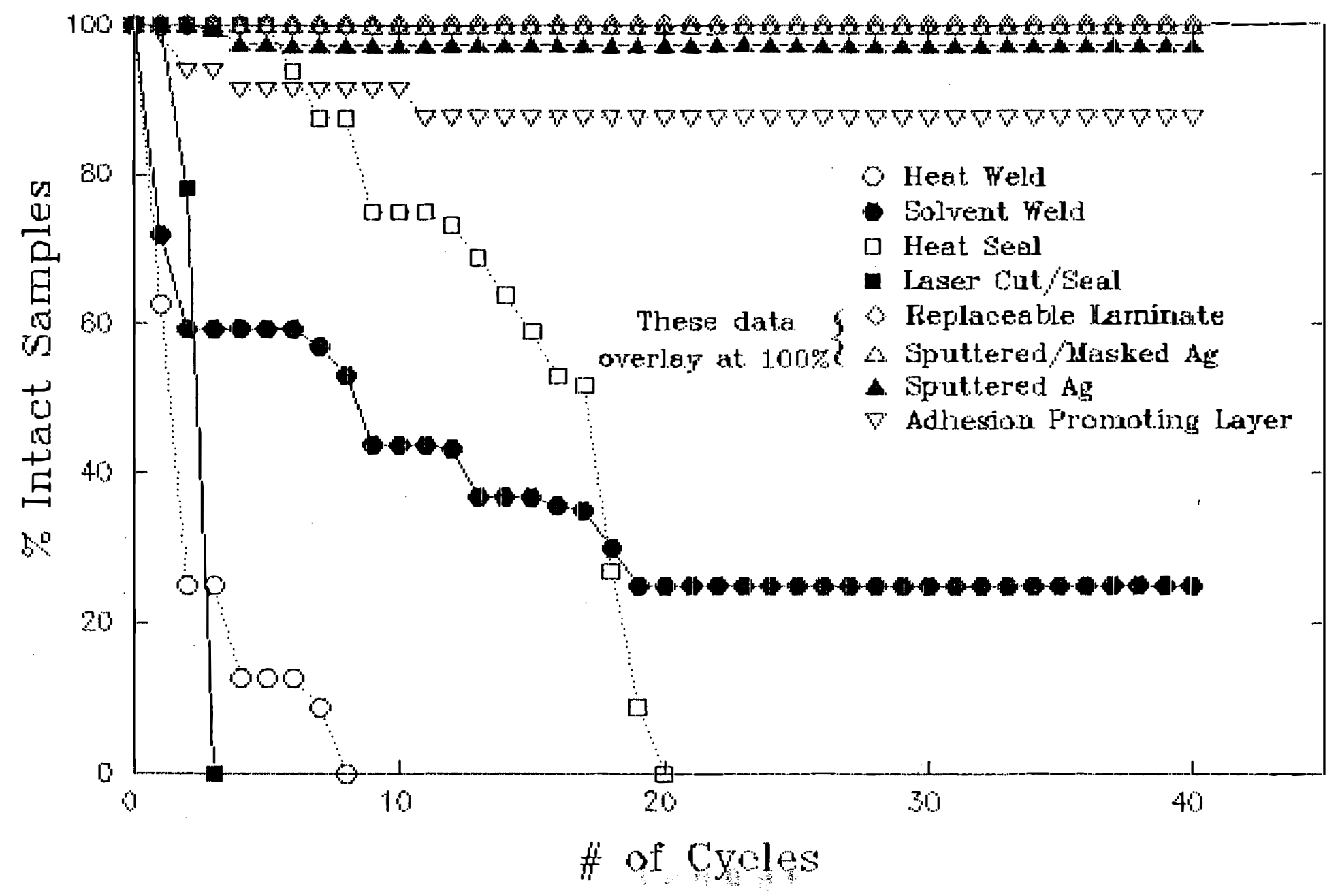

Figure 5-7. Percent-intact samples vs. number of cycles for 9-x-24-inch ECP-305 in cyclic tunneling test . 


\subsection{Conclusions and Recommendations}

Results from a series of static water immersion and cyclic exposure tunneling experiments have identified a number of approaches that offer increased resistance to delamination in silvered-polymer reflector materials. One approach uses an elevated-temperature thermal treatment of reflectors laminated to their substrate material. A second approach substitutes an alternative edge tape (Tedlar) for the standard ECP-244. Another promising approach under consideration uses alternative deposition processes such as sputtering rather than evaporation of silver onto the polymer film.

Based upon the results presented in this report, the following recommendations can improve the tunnel resistance of silvered-polymer reflectors:

(1) Thermally treat the ECP-305/substrate construction (after lamination) at a minimum of $70^{\circ} \mathrm{C}$ for 40 hours. If possible, treat at $80^{\circ} \mathrm{C}$. To avoid possible damage to the reflector material, do not exceed $80^{\circ} \mathrm{C}$.

(2) Based upon the results for curved substrate samples, thermally treat reflector elements configured as close to their final form as possible.

(3) If thermal treatment is infeasible, or if an additional safety factor is desired, use Tedlar tape to protect all edges.

(4) Avoid bare aluminum substrate material to prevent aluminum hydroxide formation that can serve as tunnel initiation sites.

(5) Explore the feasibility of incorporating alternative deposition methods (such as sputtering) into the production process of commercial silvered-polymer reflector materials. 


\subsection{References}

1. Jorgensen, G., and Schissel, P., "Optical Performance and Durability of Silvered Polymer Mirrors," Metallized Plastics 1: Fundamentals and Applied Aspects, ed. by K. L. Mittal and J. R. Susko, Plenum Press, New York, 1989, pp. 79-92.

2. Schissel, P., et al., "Silvered Polymer Mirrors - Corrosion Inhibition," SERI letter report in fulfillment of milestone C2-3, Golden, CO, September 1, 1989.

3. Alpert, D. J., et al., "Solar Concentrator Development in the United States," presented at the International Energy Agency meeting, Switzerland, August 1990.

4. Baum, B., and Cross, S., "Protective Treatments for Membrane Heliostat Mirrors," Final Report by Springborn Materials Science Division of Springborn Laboratories, Inc., Enfield, CT. Prepared under SERI subcontract HX-8-07247-1 for the period January 1988 - July 1988.

5. Shutt, J. D., et al., "Anti-Soiling Solar Reflector Research," Final Topical Report by Georgia Tech Solar Thermal Advanced Research Center, Atlanta, GA. Prepared under SERI subcontract X-7-07029-1 for the period March 1, 1987 - April 30, 1989.

6. "Soiling Rates and Cleaning Techniques for ECP-300," Final Report by Industrial Solar Technology, Denver, CO. Prepared under SERI subcontract HL-9-19017-1, July 31, 1989.

7. Adhesion Fundamentals and Practice, United Kingdom, Ministry of Technology, New York, Elsevier, 1970, pp. 52-57.

8. Benson, B. A., private communication, 3M Corporation, St. Paul, MN.

9. Schissel, P., et al., "Interim Report on Polymer Film-to-Silver Adhesion," SERI letter report in fulfillment of milestone C2-3, Golden, CO, April 1989.

10. Schissel, P., et al., "Tunneling and Delamination in Silvered Polymer Mirrors," SERI letter report in fulfillment of milestone 2C, Golden, CO, September 1990.

11. Dowdy, S., and Wearden, S., Statistics for Research, New York, John Wiley and Sons, 1983, pp. 322-349.

12. C. Lipson and N. J. Sheth, Statistical Design and Analysis of Engineering Experiments, McGraw Hill, 1973, pp. 251, 252, 178.

13. Ibid., pp. 456-467.

14. "Design Cube," Qinas, Inc., Littleton, CO, 1986.

15. "Design Expert ${ }^{\mathrm{tm}}, "$ Stat-Ease, Inc., Minneapolis, MN, 1989. 


\begin{tabular}{|c|c|c|c|}
\hline Document Control Page & $\begin{array}{l}\text { 1. SERI Report No. } \\
\text { SERITP-257-4419 }\end{array}$ & $\begin{array}{l}\text { 2. NTIS Accession No. } \\
\text { DE } 91002200\end{array}$ & 3. Recipient's Accession No. \\
\hline \multirow{2}{*}{\multicolumn{3}{|c|}{$\begin{array}{l}\text { 4. Title and Subtitle } \\
\text { Improved Tunnel Resistance of Silvered-Polymer Mirrors }\end{array}$}} & $\begin{array}{l}\text { 5. Publication Date } \\
\text { September } 1991\end{array}$ \\
\hline & & & 6. \\
\hline \multicolumn{3}{|c|}{$\begin{array}{l}\text { 7. Author(s) } \\
\text { G. Jorgensen, P. Schissel, C. Kennedy, Y. Shinton, D. Powell, J. Siebarth }\end{array}$} & 8. Performing Organization Rept. No. \\
\hline \multirow{2}{*}{\multicolumn{3}{|c|}{$\begin{array}{l}\text { 9. Performing Organization Name and Address } \\
\text { Solar Energy Research Institute } \\
1617 \text { Cole Blvd. } \\
\text { Golden, CO } 80401-3393\end{array}$}} & $\begin{array}{l}\text { 10. ProjectTaskWork Unit No. } \\
\text { SE112032 }\end{array}$ \\
\hline & & & $\begin{array}{l}\text { 11. Contract (C) or Grant (G) No. } \\
\text { (C) } \\
\text { (G) }\end{array}$ \\
\hline \multirow{2}{*}{\multicolumn{3}{|c|}{$\begin{array}{l}\text { 12. Sponsoring Organization Name and Address } \\
\text { Solar Energy Research Institute } \\
1617 \text { Cole Blvd. } \\
\text { Golden, CO } 80401\end{array}$}} & $\begin{array}{l}\text { 13. Type of Report \& Period Covered } \\
\text { Technical Report }\end{array}$ \\
\hline & & & 14. \\
\hline \multicolumn{4}{|l|}{ 15. Supplementary Notes } \\
\hline \multicolumn{4}{|c|}{$\begin{array}{l}\text { This report documents the research performed at the Solar Energy Research Institute (SERI) during fiscal year } 1991 \text { to develop } \\
\text { ways to prevent delamination failure (known as tunneling) of silvered-polymer reflector materials. Several promising approaches } \\
\text { have been identified and demonstrated that substantially reduce such failures. These approaches include (1) use of Tedlar edge } \\
\text { tape rather than the recommended ECP-244 tape, (2) thermal treatment of laminated reflector/substrate consinctions, and (3) } \\
\text { application of silver to the polymer film through an altemative deposition process. Approaches } 1 \text { and } 2 \text { offer readily available } \\
\text { engineering solutions to the delamination problem. Approaches } 2 \text { and } 3 \text { provide tunnel resistance over the entire surface of the } \\
\text { reflector material, including the edges. }\end{array}$} \\
\hline \multicolumn{4}{|c|}{$\begin{array}{l}\text { 17. Document Analysis } \\
\text { a. Descriptors } \\
\text { tunneling, delamination, metallized polymers } \\
\text { b. Identifiers/Open-Ended Terms }\end{array}$} \\
\hline \multicolumn{4}{|l|}{$\begin{array}{l}\text { c. UC Categories } \\
234\end{array}$} \\
\hline \multirow{2}{*}{\multicolumn{3}{|c|}{$\begin{array}{l}\text { 18. Availability Statement } \\
\text { National Technical Information Service } \\
\text { U.S. Department of Commerce } \\
\text { 5285 Port Royal Road } \\
\text { Springfield, VA } 22161\end{array}$}} & $\begin{array}{l}\text { 19. No. of Pages } \\
32\end{array}$ \\
\hline & & & $\begin{array}{l}\text { 20. Price } \\
\text { A03 }\end{array}$ \\
\hline
\end{tabular}

Form No. 0069E (6-30-87) 